\title{
Commercially available versus home produced egg media for isolation of mycobacteria
}

\author{
G Harris, A Rayner, B Watt
}

\begin{abstract}
Aims-To compare the growth of clinical isolates of mycobacteria on in-house and commercial egg media.

Methods-Fresh test media were inoculated with dilutions of the test organisms and growth, colonial morphology and microscopic appearance were compared blindly by two observers. The process was repeated after the test media had been stored for three months. The user friendliness of each of the test media was also assessed.

Results-There was no difference in the microscopic appearance of any given mycobacterial species between different media. All of the test media grew the test species, although Mycobacterium bovis required four weeks on BioMerieux media, compared with two weeks on the other media. There was little obvious effect of storage on any of the media, except with $M$ kansasii. Individual species gave characteristic colonial appearances on inhouse media; all of the commercial media gave non-specific colonial appearances that made presumptive identification very difficult. There were clear differences in the user friendliness of different media. Conclusions-Although commercially available egg media in general gave good growth of mycobacteria, only in-house media combined good growth with useful colonial features.

( $($ Clin Pathol 1995;48:564-567)
\end{abstract}

Keywords: Mycobacteria, culture media, egg media.

Egg based media have been used for many years for the isolation and culture of mycobacteria. ${ }^{1}$ Such media are based on egg with a buffered salt solution to which is added either glycerolfor example, International Union against Tuberculosis (IUT) medium, ${ }^{2}$ or sodium pyruvate-for example, Stonebrink's medium. ${ }^{3}$ Larger laboratories prepare their own in-house media, but many laboratories purchase commercially available media. We were not aware of any data on the comparative performance of egg based media, so decided to compare our own egg in-house media with the corresponding commercially available media.

\section{Methods}

TEST ISOLATES

The following clinical isolates from the collection of the Scottish Mycobacterial Reference
Laboratory (SMRL) were tested: Mycobacterium tuberculosis (three strains); $M$ malmoense (three strains); $M$ avium complex (three strains); $M$ bovis (two strains); $M$ kansasii (two strains); and $M$ fortuitum, $M$ marinum, $M$ gordonae (one strain each). All strains were freshly subcultured onto egg media before use.

TEST MEDIA

The two in-house SMRL media tested were IUT glycerol egg medium ${ }^{2}$ and pyruvate egg medium based on Stonebrink's medium ${ }^{3}$ with added citrate. Full details are given in our recent review. ${ }^{4}$

The following companies were contacted and asked if they were willing to supply commercially available media in sufficient quantity for the trial, within a three month period: Difco Ltd, West Molesey, Surrey; Mast Laboratories Ltd, Bootle, Merseyside; Unipath Ltd, Basingstoke, Hampshire; BioMerieux (UK) Ltd, Basingstoke, Hampshire; and Becton Dickinson UK Ltd, Cowley, Oxford. All, with one exception, were able to supply us with both glycerol and pyruvate egg media. In addition, Cherwell Laboratories, Bicester, Oxford, produced trial "commercial" versions of our own home-made media for comparison. Thus, we were able to compare five commercial egg media with our own in-house glycerol and pyruvate egg media.

The media were divided into two aliquots; one was tested immediately and the other was stored according to the manufacturer's instructions (at $4^{\circ} \mathrm{C}$ in the case of commercial media, at room temperature for in-house media) for three months, then retested.

\section{PREPARATION OF INOCULA AND INOCULATION}

OF MEDIA

For each of the test strains, growth from a glycerol slope was removed into a glass McCartney bottle containing glass beads and $0.4 \mathrm{ml}$ sterile distilled water. The bottle was placed in a bag and vortexed to produce a smooth suspension. The suspension was then transferred into a glass tube and using a colorimeter (wavelength $710 \mathrm{~mm}$ ) was then adjusted to a final concentration of approximately $5 \times 10^{7}$ $\mathrm{cfu} / \mathrm{ml}$ as determined by viable counts. Tenfold dilutions of this final suspension were prepared in sterile distilled water and using a 3 micron loop each dilution was seeded onto each test slope to give final inocula from $5->5000 \mathrm{cfu}$ (table 1).

Three slopes of each type of medium were inoculated with each of the five suspensions 
Table 1 Inoculum size used

\begin{tabular}{lll}
\hline Inoculum & $c f u / m l$ (approximate) & $\begin{array}{l}\text { Approximate number of colonies inoculated } \\
\text { to slope }\end{array}$ \\
\hline 1 & $5 \times 10^{6}$ & $<5000$ \\
2 & $5 \times 10^{5}$ & $1000-5000$ \\
3 & $5 \times 10^{4}$ & $100-500$ \\
4 & $5 \times 10^{3}$ & $10-50$ \\
5 & $5 \times 10^{2}$ & $1-5$ \\
\hline
\end{tabular}

Table 2 Visual assessment of growth and colonial appearance

\begin{tabular}{|c|c|c|c|}
\hline \multicolumn{2}{|l|}{ Assessment of growth } & \multicolumn{2}{|c|}{ Assessment of colonial appearance } \\
\hline No. of colonies & Grade & Appearance & Grade \\
\hline $\begin{array}{l}1-10 \\
11-50 \\
51-100 \\
101-200 \\
201-300 \\
301-400 \\
401-500 \\
>500 \text { but not confluent } \\
\text { Confluent growth }\end{array}$ & $\begin{array}{l}1 \\
2 \\
3 \\
4 \\
5 \\
6 \\
7 \\
8 \\
9\end{array}$ & $\begin{array}{l}\text { Trace of growth } \\
\text { Very dysgonic growth } \\
\text { Dysgonic growth } \\
\text { Eugonic growth }\end{array}$ & $\begin{array}{l}\text { A } \\
\text { B } \\
\text { C } \\
\text { D }\end{array}$ \\
\hline
\end{tabular}

for each of the test strains. The slopes were incubated at $37^{\circ} \mathrm{C}$ and examined weekly. The amount of growth and the colonial morphology were recorded (see below). Each slope was incubated until maximum growth was achieved or for a total of five weeks. A smear was made of each species from each of the 12 types of media, stained by Ziehl-Neelsen and examined at $\times 40$ using an oil immersion lens. The following criteria were recorded: presence or absence of beading; ease of emulsification; the depth of stain; and size.

The whole procedure was repeated after three months using the stored media (see above).

\section{ASSESSMENT OF GROWTH AND COLONIAL MORPHOLOGY}

The amount of growth was assessed visually and graded as shown in table 2 .

\section{USER FRIENDLINESS}

The user friendliness of each of the test media and their containers was also noted, especially in relation to ease of access, visibility, resistance of media to scoring, cap linings, angle and area of media slope, amount of condensation, and resistance to breakage.

\section{Results}

ZIEHL-NEELSEN STAINED SMEARS OF GROWTH There were no differences in the microscopic appearance of Ziehl-Neelsen stained smears of any given species between different media.

SPEED OF GROWTH

The results are shown in table 3.

\section{Fresh media}

All of the test media grew the test strains of $M$ tuberculosis within two to three weeks of incubation. For $M$ bovis, visible colonies on pyruvate (the most important medium for this species) were produced within two weeks on SMRL, Mast, Difco, Unipath, and Cherwell media but required four weeks in BioMerieux media.

For $M$ avium, colonies were produced in the shortest time on BioMerieux, Cherwell and Difco media. For $M$ malmoense, all media grew the test strains within two to three weeks, except for the Unipath media, in which two of the strains required three weeks on both media and one strain grew poorly. All media produced visible colonies of $M$ kansasii within two to three weeks. In the case of $M$ marinum, SMRL and Unipath pyruvate media and both types of Mast and Difco media showed visible colonies of $M$ marinum after one week of incubation. The remaining media required two weeks.

In the case of the test strain of $M$ fortuitum, all of the test media produced visible colonies within one week. For $M$ gordonae, both of the Difco media and the Cherwell and BioMerieux media produced colonies within one week; the other media required two (three for Unipath pyruvate media) weeks of incubation for visible colonies to appear.

Table 3 Speed of growth on various media

\begin{tabular}{|c|c|c|c|c|c|c|c|c|c|c|c|c|c|}
\hline \multirow[b]{3}{*}{ Test strain } & & \multicolumn{12}{|c|}{ No. of weeks of incubation to produce visible colonies on: } \\
\hline & & \multicolumn{2}{|l|}{$S M R L$} & \multicolumn{2}{|l|}{ Mast } & \multicolumn{2}{|l|}{ Difco } & \multicolumn{2}{|l|}{ Unipath } & \multicolumn{2}{|l|}{ Cherwell } & \multicolumn{2}{|c|}{ BioMerieux } \\
\hline & & $G$ & $P$ & $G$ & $P$ & $G$ & $P$ & $G$ & $P$ & $G$ & $P$ & $G$ & $P$ \\
\hline $\begin{array}{l}M \text { tuberculosis } \\
M \text { bovis } \\
M \text { avium }\end{array}$ & $\begin{array}{l}\text { Strain A } \\
\text { Strain B } \\
\text { Strain C } \\
\text { Strain K } \\
\text { Strain L }\end{array}$ & $\begin{array}{l}2(2) \\
2(3) \\
2(2) \\
4(2) \\
N G(3)\end{array}$ & $\begin{array}{l}2(2) \\
2(3) \\
2(2) \\
2(2) \\
2(2)\end{array}$ & $\begin{array}{l}2(2) \\
2(2) \\
2(2) \\
3(3) \\
3(3)\end{array}$ & $\begin{array}{l}2(2) \\
2(3) \\
2(2) \\
2(3) \\
2(3)\end{array}$ & $\begin{array}{l}2(2) \\
2(3) \\
2(2) \\
3(2) \\
4(3)\end{array}$ & $\begin{array}{l}2(2) \\
2(2) \\
2(2) \\
2(2) \\
2(2)\end{array}$ & $\begin{array}{l}2(3) \\
2(3) \\
2(3) \\
4(3) \\
2(3)\end{array}$ & $\begin{array}{l}2(2) \\
2(3) \\
2(3) \\
2(2) \\
2(3)\end{array}$ & $\begin{array}{l}2(3) \\
2(3) \\
2(3) \\
4(3) \\
N G(3)\end{array}$ & $\begin{array}{l}2(3) \\
2(3) \\
2(3) \\
2(3) \\
2(3)\end{array}$ & $\begin{array}{l}2(3) \\
2(3) \\
3(3) \\
\text { NG (3) } \\
\text { NG (3) }\end{array}$ & $\begin{array}{l}2 \text { (3) } \\
2 \text { (3) } \\
3 \text { (3) } \\
4(3) \\
4(3)\end{array}$ \\
\hline $\begin{array}{l}M \text { malmoense } \\
M \text { kansasii } \\
M \text { marinum } \\
M \text { fortuitum* } \\
M \text { gondonae* }\end{array}$ & $\begin{array}{l}\text { Strain G } \\
\text { Strain H } \\
\text { Strain J } \\
\text { Strain D } \\
\text { Strain E } \\
\text { Strain F } \\
\text { Strain M } \\
\text { Strain N } \\
\text { Strain R } \\
\text { Strain P } \\
\text { Strain S }\end{array}$ & $\begin{array}{l}3(1) \\
3(1) \\
2(1) \\
3(2) \\
2(2) \\
2(2) \\
2(3) \\
2(3) \\
2(2) \\
1 \\
2\end{array}$ & $\begin{array}{l}1(1) \\
3(1) \\
2(1) \\
3(2) \\
2(2) \\
2(2) \\
2(4) \\
3(3) \\
1(2) \\
1 \\
2\end{array}$ & $\begin{array}{l}3(1) \\
3(1) \\
2(1) \\
3(4) \\
2(3) \\
2(2) \\
2(4) \\
2(3) \\
1(2) \\
1 \\
2\end{array}$ & $\begin{array}{l}1(1) \\
2(1) \\
22(1) \\
3(2) \\
2(2) \\
2(2) \\
2(3) \\
3(3) \\
1(2) \\
1 \\
2\end{array}$ & $\begin{array}{l}1(1) \\
1(1) \\
1(1) \\
3(2) \\
2(3) \\
2(2) \\
2(4) \\
2(3) \\
1(2) \\
1 \\
1\end{array}$ & $\begin{array}{l}1(1) \\
2(1) \\
1(1) \\
3(2) \\
2(3) \\
2(2) \\
2(3) \\
3(3) \\
1(2) \\
1 \\
1\end{array}$ & $\begin{array}{l}2(1) \\
2(2) \\
2(1) \\
3(4) \\
3(3) \\
4(2) \\
2(\mathrm{NG}) \\
2(3) \\
2(2) \\
1 \\
2\end{array}$ & $\begin{array}{l}1(1) \\
2(2) \\
2(1) \\
3(3) \\
3(2) \\
4(2) \\
2(3) \\
3(4) \\
1(2) \\
1 \\
3\end{array}$ & $\begin{array}{l}1(1) \\
3(1) \\
1(1) \\
2(2) \\
2(2) \\
2(3) \\
2 \text { (NG) } \\
3(3) \\
2 \text { (NG) } \\
1 \\
2\end{array}$ & $\begin{array}{l}1(1) \\
3(1) \\
2(1) \\
2(2) \\
2(2) \\
2 \text { (3) } \\
3 \text { (NG) } \\
3 \text { (NG) } \\
2 \text { (NG) } \\
1 \\
1\end{array}$ & $\begin{array}{l}1(1) \\
1(1) \\
1(1) \\
3(3) \\
2(3) \\
2(3) \\
2(3) \\
2(4) \\
2(2) \\
1 \\
2\end{array}$ & $\begin{array}{l}1(1) \\
1(1) \\
1(1) \\
3(3) \\
2(2) \\
2(3) \\
2(4) \\
2(4) \\
2(2) \\
1 \\
1\end{array}$ \\
\hline
\end{tabular}

Results in brackets = after storage; $G=$ glycerol media; $P=$ pyruvate media; $N G=$ no growth after five weeks of incubation.

* These strains failed to grow on subculture for inoculation onto stored media. 
Table 4 Characteristics of growth and effect of storage on defined medium

\begin{tabular}{|c|c|c|c|c|c|c|c|c|c|c|c|c|c|}
\hline \multirow[b]{2}{*}{ Test strain } & & \multicolumn{2}{|l|}{$S M R L$} & \multicolumn{2}{|l|}{ Mast } & \multicolumn{2}{|l|}{ Difco } & \multicolumn{2}{|l|}{ Unipath } & \multicolumn{2}{|l|}{ Cherwell } & \multicolumn{2}{|l|}{ BioMerieux } \\
\hline & & $G^{*}$ & $P$ & $G$ & $P$ & $G$ & $P$ & $G$ & $P$ & $G$ & $P$ & $G$ & $P$ \\
\hline \multirow[t]{3}{*}{$M$ tuberculosis } & A & )) & D) & $8 \mathrm{D}(3 \mathrm{D})$ & $8 \mathrm{D}(3 \mathrm{D})$ & & 81 & $8 \mathrm{D}$ & $8 \mathrm{D}$ & $8 \mathrm{D}(4 \mathrm{D})$ & $8 \mathrm{D}$ & $2 \mathrm{D}(8 \mathrm{D})$ & $4 \mathrm{D}(8 \mathrm{D})$ \\
\hline & B & ) & D) & $8 \mathrm{D}(4 \mathrm{D})$ & 8D (8D) & 81 & 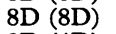 & 8 & & )) & ) & ) & D) \\
\hline & & $8 \mathrm{D}$ & D) & (4D) & D) & $8 \mathrm{D}$ & $8 \mathrm{I}$ & & ) & $8 \mathrm{D}$ & & 1. & (D) \\
\hline \multirow{2}{*}{$M$ bovis } & $\mathrm{K}$ & $2 \mathrm{I}$ & D) & $4 \mathrm{C}(4 \mathrm{C})$ & $8 \mathrm{D}(4 \mathrm{C})$ & $4 C(5 C)$ & $8 \mathrm{D}(5 \mathrm{D})$ & $4 C(4 C)$ & $8 \mathrm{D}(4 \mathrm{D})$ & $1 \mathrm{C}(6 \mathrm{C})$ & $1 \mathrm{D}(6 \mathrm{D})$ & NG (4B) & $2 \mathrm{C}(4 \mathrm{~B})$ \\
\hline & & B) & & $8 \mathrm{C}(3 \mathrm{~B})$ & $8 \mathrm{D}$ & $1 \mathrm{D}(4 \mathrm{C})$ & D) & $8 C(4 B)$ & $9 \mathrm{D}(4 \mathrm{C})$ & NG (4C) & D) & NG (3A) & $1 B(4 B)$ \\
\hline \multirow[t]{2}{*}{$M$ malmoense } & $\begin{array}{l}\text { Strain D } \\
\text { Strain E }\end{array}$ & $\begin{array}{l}8 \mathrm{C}(8 \mathrm{C}) \\
8 \mathrm{C}(8 \mathrm{C})\end{array}$ & C) & $\begin{array}{l}8 \mathrm{C}(8 \mathrm{C}) \\
8 \mathrm{C}(8 \mathrm{C})\end{array}$ & $\begin{array}{l}8 \mathrm{C}(8 \mathrm{C}) \\
8 \mathrm{D}(\mathrm{DD})\end{array}$ & $\begin{array}{l}8 \mathrm{C}(8 \mathrm{C}) \\
8 \mathrm{C}(8 \mathrm{C})\end{array}$ & $\begin{array}{l}8 \mathrm{C}(8 \mathrm{C}) \\
8 \mathrm{C}(8 \mathrm{C})\end{array}$ & $\begin{array}{l}8 \mathrm{C}(8 \mathrm{C}) \\
8 \mathrm{C}(\mathrm{8C})\end{array}$ & $\begin{array}{l}8 \mathrm{C}(8 \mathrm{C}) \\
2 \mathrm{D}(8 \mathrm{D})\end{array}$ & $\begin{array}{l}8 \mathrm{C}(8 \mathrm{C}) \\
8 \mathrm{C}(8 \mathrm{C})\end{array}$ & & $\begin{array}{l}8 \mathrm{C}(8 \mathrm{C}) \\
8 \mathrm{C}(8 \mathrm{C})\end{array}$ & $\begin{array}{l}8 \mathrm{C}(8 \mathrm{C}) \\
8 \mathrm{D}(8 \mathrm{C})\end{array}$ \\
\hline & & & D) & $8 \mathrm{C}$ & $8 \mathrm{D}$ & $8 C(8 B)$ & $8 C(8 D)$ & NG (8C) & $5 C(8 D)$ & $8 \mathrm{C}(8 \mathrm{C})$ & 8D) & $8 \mathrm{C}(8 \mathrm{C})$ & $8 \mathrm{D}(8 \mathrm{C})$ \\
\hline \multirow[t]{3}{*}{$\begin{array}{l}M \text { avium } \\
\text { complex }\end{array}$} & & & & & & & & & & & & & \\
\hline & & 8B $(8$ & OD & & & & & & & & & & \\
\hline & & $8 \mathrm{~B}(8 \mathrm{~B})$ & & $8 \mathrm{C}($ & & $8 \mathrm{C}(8 \mathrm{C})$ & $8 \mathrm{D}$ & $8 \mathrm{D}(8$ & $8 \mathrm{D}(8 \mathrm{C})$ & $8 \mathrm{C}(8 \mathrm{C})$ & & & \\
\hline \multirow{2}{*}{$M$ kansasii } & Strain $M$ & 9D (1D) & 8D (1D) & 7C (1D) & 1D) & 9D (1D) & 9D & 9D (NG) & $8 \mathrm{D}$ & 2D (NG) & ID & 8D (1D) & $8 \mathrm{D}$ (1D) \\
\hline & & $8 D(2 D)$ & 5D (2D) & $4 \mathrm{C}(2 \mathrm{D})$ & 4D (2D) & 6D (2D) & 4D (2D) & $8 \mathrm{D}(2 \mathrm{D})$ & $3 \mathrm{D}(2 \mathrm{D})$ & $3 \mathrm{D}(2 \mathrm{D})$ & $1 \mathrm{D}$ (NG) & 4D (2D) & 4D (2D) \\
\hline & & $8 \mathrm{D}(7 \mathrm{D})$ & 8D (7D) & $8 \mathrm{D}(5 \mathrm{C})$ & $9 \mathrm{D}(5 \mathrm{D})$ & $9 \mathrm{D}(9 \mathrm{D})$ & 9D (7D) & $1 \mathrm{D}(5 \mathrm{D})$ & 9D (7D) & 2D (NG) & 5D (NG) & $8 \mathrm{~B}(7 \mathrm{D})$ & $8 \mathrm{~B}(7 \mathrm{D})$ \\
\hline 20 & & & $8 \mathrm{D}$ & & $3 I$ & $8 \mathrm{D}$ & $8 \mathrm{I}$ & $8 \Gamma$ & $7 \mathrm{I}$ & $8 \mathrm{I}$ & $8 \mathrm{I}$ & & \\
\hline$M$ gordonae $^{* *}$ & Strain C & $9 \mathrm{D}$ & $8 \mathrm{D}$ & $8 \mathrm{D}$ & $8 \mathrm{D}$ & $8 \mathrm{D}$ & $8 \mathrm{D}$ & $8 \mathrm{D}$ & $7 \mathrm{D}$ & 9D & $8 \mathrm{D}$ & $8 \mathrm{D}$ & $8 \mathrm{D}$ \\
\hline
\end{tabular}

Results in brackets = after storage; $\mathrm{G}=$ glycerol media; $\mathrm{P}=$ pyruvate media; $\mathrm{NG}=$ no growth after five weeks of incubation

Results in brackets $=$ after storage; $G=$ glycerol media; $P=$ pyruvate media; $N G=$ no growth after five weeks of incubation. * Growth was assessed quantitatively as follows: $1=1-10$ colonies; $2=11-50$ colonies; $3=51-100$ colonies; $7=401-500$ colonies; $8=>500$ but not confluent growth; $9=$ confluent growth.
$301-400$ coll

Colonial appearance was assessed visually as follows: $A=$ trace of growth; $B=$ very dysgonic growth; $C=$ dysgonic growth; $D=$ eugonic growth

** These strains failed to grow on subculture for the repeat tests on stored media.

STORED MEDIA

For $M$ tuberculosis, storage had least effect in Mast, Difco and SMRL media, but increased the time required for colonies to appear on both types of Cherwell and BioMerieux media. Storage reduced the time required for colonies of $M$ avium to appear on most test media. By contrast, storage increased the time required in the case of $M$ kansasii.

For many media types, the inoculation of both types of slope (glycerol and pyruvate) would have ensured a speedier recognition of colony formation than if only one type of medium had been used.

\section{CHARACTERISTICS OF GROWTH}

The results are shown in table 4. Growth of the $M$ tuberculosis strains was much less luxuriant on BioMerieux media than on the other media; this was also true for the $M$ bovis strains.

In the case of $M$ bovis, the contrast between the very good growth on SMRL pyruvate medium and poor (or no) growth on SMRL glycerol medium is a very useful distinguishing feature; this was less pronounced for other makes of media. In the case of Cherwell media, one strain showed this feature, the other grew poorly on both Cherwell media, as was the case for both of the strains on both BioMerieux media. The performance of BioMerieux media was somewhat improved on storage; for most other media growth was less luxuriant on stored media. In the case of the SMRL glycerol medium, storage improved the growth of $M$ bovis on glycerol media but thereby reduced the distinguishing feature of differential growth on glycerol and pyruvate media.

For $M$ kansasii, one strain (M) grew well on all media except Cherwell media, but the other (N) only showed luxuriant growth on SMRL and Unipath media. Storage reduced (noticeably in some cases) the performance of all media.

For $M$ marinum, all media except Cherwell media performed satisfactorily, but storage again reduced the performance of all media.
All media gave very good growth of $M$ avium, $M$ gordonae and $M$ fortuitum strains, except for Mast glycerol media, and Cherwell pyruvate media, which gave poor growth of the $M$ fortuitum strain.

\section{DIFFERENTIAL APPEARANCES ON THE TEST} MEDIA

Apart from SMRL media, it was very noticeable that with the other test media there was little or no difference between the colonial appearance of different species. Thus, $M$ avium complex strains were indistinguishable from $M$ tuberculosis or $M$ bovis strains. The poor differential growth of $M$ bovis was also a feature-that is, little or no difference in growth in glycerol and pyruvate media, except with SMRL media.

GROWTH OF SMALL INOCULA

There was little to choose between the test media in terms of ability to support the growth of small inocula-that is, the smallest inoculum consistently yielding visible colonies $(10-50 \mathrm{cfu})$ was similar for all glycerol media and all pyruvate media, although the use of both media together would have led to recovery of lower inocula than if only one had been used.

\section{USER FRIENDLINESS OF THE TEST MEDIA}

SMRL and Cherwell media were prepared in Universal bottles, easy to handle with easily removable plastic screw caps. The media had large surface areas for inoculating, with easy access through a wide neck. Colonies were easily visible through the glass. These bottles are reasonably strong but as they are glass they are potentially breakable.

Difco media were prepared in a slightly smaller version of the SMRL and Cherwell bottle.

Unipath media were supplied in heavy, thick glass bottles with stiff metal caps. The rubber cap linings tended to stick to the bottle, making first-time opening difficult. The wide neck gave 
good access but the angle of the slope made the possibility of "scoring" the slope with a loop quite likely. The thickness of the glass and the considerable amount of condensation made for rather poor visibility, but they are very strong bottles and breakage was considered very unlikely.

BioMerieux media were supplied in tubes that were unstable unless placed in special racks. The length of the tubes, with a long slant of medium, increased the risk of contamination and transfer of organisms onto the shaft of the inoculating loop or swab unless great care was taken. Visibility was good through the thin glass but the narrow necks made access difficult and the thin glass increased the possibility of breakage.

Mast media were supplied in bottles with narrow necks and a wide slant of medium. Access was limited through the narrow neck, and the angle of the slant increased the likelihood of inadvertently stabbing the medium. In our experience, it was only possible to utilise a small portion of the slant when using loops or swabs to inoculate the bottles. The shape of the bottle and the thick glass made visibility poor but again meant resistance to breakage was good.

For any vial, there is a conflict between the use of glass thin enough to see the small colonies often encountered with mycobacteria other than tuberculosis such as $M$ malmoense and the need for the vial to survive all mechanical shocks. This requires a balance between these two conflicting objectives; none of the vials completely fulfil both requirements.

\section{Discussion}

In spite of recent advances in the laboratory diagnosis of tuberculosis, the use of egg based media remains the cornerstone of the primary isolation of mycobacteria, their subculture and, in many centres, susceptibility testing and identification. Some laboratories prepare their own media but this is very labour intensive, leading many to purchase commercially made media. In both cases the quality of egg based media is crucial to optimal recovery and recognition of mycobacteria from clinical samples, especially of demanding mycobacteria such as $M$ malmoense, yet there have been, to our knowledge, no systematic comparative studies of commercial culture media.

Our study was performed by two independent observers (AR and $\mathrm{GH}$ ) who assessed the media as far as possible blindly (although the shape of the bottles was often characteristic of a given medium and precluded complete "blinding").

It is clear that, in general, most media recovered most strains of mycobacteria satisfactorily and that storage for three months made little difference. However, most commercial media gave little or no characteristic colonial morphology with any of the test strains (for example, $M$ tuberculosis looked like $M$ avium). This is a major drawback, certainly in centres handling large numbers of samples; colonial morphology is an important presumptive guide in experienced hands and will influence choice of identification tests (including use of probes) and, often, therapeutic decisions. We found our own SMRL media to be greatly superior in this regard.

User friendliness is another important consideration. Some media were supplied in very thick bottles with poor access, but unlikely to break, while the BioMerieux media were supplied in thin glass tubes that are more liable to breakage but give good visibility. Clearly, there has to be a compromise between high visibility and low "breakability"; the SMRL and Cherwell glass bottles provide such a compromise, but are nevertheless potentially breakable. Further development of user friendly, unbreakable containers is required.

We are aware that our study can be criticised for its lack of complete "blindness" and the use of laboratory strains, but believe it provides useful information for bacteriology laboratories culturing mycobacteria. On the basis of the results, we believe that of the test media, our own SMRL media provide the best compromise and that, as a busy mycobacterial unit, we have no evidence to recommend their replacement by any of the commercial media that are presently available.

Quality control of mycobacterial culture media is important. The use of a wide range of test species, including demanding mycobacteria and, wherever possible, fresh clinical isolates is important to ensure that optimal recovery is obtained from clinical samples. This is especially so for laboratories producing inhouse media that isolate few strains per year.

We are grateful to the commercial companies for their generosity in supplying media at substantially reduced prices and to Miss C Smith for secretarial support.

1 Dorset M. Egg medium for cultivation of tubercle bacilli. Science 1903;17:374-5.

2 International Union Against Tuberculosis. 1955 Year Book: 89 .

3 Stonebrink B. Tubercle bacilli and pyruvic acid. Proc R Neth Tub Assoc 1957;44:67-74.

4 Watt B, Rayner A, Harris G. Modern methods in mycobacteriology. Rev Med Microbiol 1993;4:97-105. 